\title{
Ensaio sobre a potência do chiru: tecnologia cosmopolítica e operador ontológico do xamanismo kaiowa
}

\author{
Augusto Ventura dos Santos ${ }^{1}$ \\ Universidade de São Paulo
}

Resumo: O presente trabalho constitui um breve ensaio sobre um elemento central do xamanismo kaiowa, as cruzes de madeira denominadas chiru. O objetivo é explorar um tópico específico de reflexão frequentemente sublinhado pelos rezadores kaiowa a respeito, o poder do chiru enquanto uma ferramenta/pessoa que age no cosmos. Ao conectar teorias locais sobre a questão (reconstituídas predominantemente através de um balanço etnográfico da literatura guarani) com alguns movimentos conceituais da teoria antropológica, pretendo demonstrar o quanto uma compreensão aprofundada desse tópico exige que revisemos algumas das antinomias fundantes do pensamento dominante sobre a "política", sobretudo aquele calcado na chave analítica da representação simbólica.

Palavras-chave: Cosmopolítica; Ontologias Múltiplas; Kaiowa; Xamanismo ameríndio. 


\title{
Essay on the power of chiru: cosmopolitical technology and ontological operator of Kaiowa shamanism
}

\begin{abstract}
This work is a brief essay on a central element of Kaiowa's shamanism, the wooden crosses called chiru. The aim is to explore a particular topic of reflection often stressed by kaiowa shamans, the power of chiru as a tool/person who acts in the cosmos. By connecting local theories on the issue (reconstructed mainly through an ethnographic review of the guarani literature) with some conceptual movements of anthropological theory, I intend to demonstrate that an in-depth understanding of this topic requires reviewing some of the founding antinomies of the dominant thinking on "politics", especially that based on the analytical key of symbolic representation.
\end{abstract}

Keywords: Cosmopolitics; Multiple Ontologies; Kaiowa; Amerindian Shamanism.

\section{Ensayo sobre la potencia del chiru: tecnología cosmopolítica y operador ontológico del chamanismo kaiowa}

\begin{abstract}
Resumen: El presente trabajo constituye un breve ensayo acerca de un elemento central del chamanismo kaiowa, las cruces de madera llamadas chiru. El objetivo es explorar un tema particular de reflexión frecuentemente enfatizado por los rezadores kaiowa, el poder del chiru como una herramienta/persona que actúa en el cosmos. Al conectar teorías locales sobre la cuestión (reconstituidas predominantemente a través de una revisión etnográfica de la literatura guaraní) con algunos movimientos conceptuales de la teoría antropológica, pretendo demostrar de que manera una comprensión profunda de ese tópico requiere revisar algunas de las antinomias fundamentales del pensamiento dominante sobre la "política", sobre todo el pensamiento basado en la clave analítica de la representación simbólica.
\end{abstract}

Palabras Clave: Cosmopolítica; Ontologías multiples; Kaiowa; Chamanismo ameríndio. 


\section{Apontamentos iniciais ${ }^{2}$}

$\mathrm{O}$ presente trabalho versará sobre um tema caro ao xamanismo kaiowa: as cruzes de madeira denominadas chiru. O intuito é explorar um aspecto das problemáticas locais sobre o tema frequentemente sublinhado pelos rezadores $^{3}$ e neglicenciado em visões superficiais dos não-indígenas: a potência do chiru enquanto uma pessoa/instrumento de ação e reflexão no cosmos. O artigo tenta, pois, dar conta do poder e da importância do chiru delineada pelas teorias kaiowa conectando-as pontualmente com alguns movimentos da teoria antropológica contemporânea que buscam esgarçar o âmbito do "político" para além dos limites estreitos estabelecidos por algumas chaves interpretativas canônicas. A partir dessa articulação entre teorias nativas e antropológicas, argumentar-se-á sobre a necessidade de interpretar o chiru em "intensidade", aproveitando-se do potencial que ele possui para nos fazer repensar a natureza de antinomias basilares do pensamento dominante sobre a "política", tais quais as dualidades sujeito/objeto e objeto/conceito.

A base empírica deste exercício foi construída predominantemente através de revisão da literatura. Busquei extrair de um conjunto de trabalhos acadêmicos uma série de reflexões e práticas kaiowa relacionadas ao chiru compondo, com isso, algo como um mosaico etnográfico, uma compilação atualizada da temática que visa trazer contribuições para a literatura na medida em que delineia uma imagem do assunto em conexão com a problemática antropológica enunciada no parágrafo anterior. É notório que os trabalhos sobre a vida e a história das populações guarani formam verdadeiras bibliotecas em razão da quantidade de textos produzidos desde os primeiros cronistas jesuítas e, por isso, a revisão bibliográfica teve caráter parcial e não exaustivo. Do mesmo modo, cabe observar que, com exceção do artigo seminal de Fábio Mura (2010) e a mais recente reflexão de Levi Marques Pereira e João Machado (prelo), não se encontram na guaraniologia trabalhos integralmente focados na temática; geralmente o assunto é abordado como uma parcela de um tema mais amplo, sendo estas parcelas que busquei selecionar e sistematizar para os fins do artigo. Importante destacar dentro deste escopo de referências as reflexões produzidas por acadêmicos kaiowa que, ainda que incipientes, vêm oferecendo contribuições decisivas para a tradução analítica desta e de outras tantas questões pertinentes ao pensamento de seu povo ${ }^{4}$. De modo complementar ao compilado de dados etnográfico de outros estudiosos, lancei mão das informações oriundas da interlocução em pesquisa que venho desenvolvendo com o casal Jorge da Silva e Floriza de Souza, proeminentes rezadores kaiowa residentes da Reserva Indígena de Dourados, Mato Grosso do Sul ${ }^{5}$.

\footnotetext{
${ }^{2} \mathrm{O}$ presente artigo é uma versão reelaborada de trabalho final para a disciplina "Ontologias Comparadas" ministrada pelo professor Renato Sztutman em 2017, no âmbito do Programa de Pós-Graduação em Antropologia Social da Universidade de São Paulo (PPGAS-USP).

3 Os xamãs kaiowa são designados por diversas expressões, tais como rezador(a), ñanderu e ñandesy, paí, cacique, etc. Optei no texto por alternar entre as expressões xamã e rezador.

4 Nominadamente três, Eliel Benites, Tonico Benites e Izaque João. É aqui também citado o artigo fruto da colaboração entre o antropólogo não indígena Levi Marques Pereira e o professor indígena da Reserva de Dourados João Machado (prelo).

5 Conheci Jorge e Floriza por ocasião da pesquisa de campo que realizei na Faculdade Indígena da Universidade Federal da Grande Dourados (FAIND-UFGD) durante os anos de 2014 e 2015. Na época desenvolvia pesquisa de mestrado sobre a participação de indígenas no ensino superior do Mato Grosso do Sul. Desde então, os dois tornaram-se queridos amigos que, sempre que preciso, me guiam pelos complexos ramos da filosofia kaiowa a qual tão bem dominam.
} 


\section{Por onde começar? Encontrando uma via de acesso para a problemática kaiowa do chiru}

Os Kaiowa ${ }^{6}$ são uma população ameríndia cujo território tradicional (tekoha guasu) localiza-se no sul do estado brasileiro do Mato Grosso do Sul. Em razão de processos de deslocamento forçado conduzidos pelo Estado e por frentes de expansão econômica, os Kaiowa foram violentamente expulsos de suas terras, vivendo hoje majoritariamente em diminutas reservas indígenas demarcadas pelo Serviço de Proteção aos Índios (SPI) no começo do século XX. Nelas, o modo de vida tradicional encontra imensas dificuldades de ser realizado plenamente; em razão disso, as famílias indígenas têm buscado uma série de alternativas, dentre as quais um vigoroso movimento de luta política em busca de seus direitos constitucionais. Os Kaiowa formam, ao lado de outros povos, o imenso mosaico linguístico e cultural das populações indígenas falantes de Guarani e, mais amplamente, de falantes de línguas Tupi-Guarani.

O chiru constituiu-se como um importante elemento distintivo dos Kaiowa com relação a outras populações ameríndias e a outros povos guarani. É quase paradigmática a imagem do rezador kaiowa como um cantador que porta, em uma das mãos, um mbaraka (instrumento chocalho que ritma as rezas) e, na outra, uma cruz de madeira. Já no período colonial, o padre Bernardo Nusdorffer identificou nos Caaguá ou Itatín (dois outros etnônimos designados a esta população nos séculos XVII, XVIII e XIX) três elementos diferenciadores dos demais indígenas que conhecia: "la creencia en un solo Dios", vestimentas semelhantes aos dos sacerdotes católicos (em especial o uso de adorno na cabeça, segundo ele semelhante a uma coroa) e, por fim, "el uso ritual de la cruz" (MELIA, GRUNBERG \& GRUNBERG, 2008: 34). Como se pode notar, os três diacríticos constituem aparentes convergências culturais com elementos do cristianismo, coisas que, segundo Melia, Grunberg e Grunberg "suscitaron entre observadores y comentadores las más fabulosas opiniones" (IDEM). Do ponto de vista dos brancos, o chiru, ao mesmo tempo que identificado como um traço característico kaiowa, logo foi objeto de variadas problematizações sobre as influências da convivência que parte dessa população experimentou com missões jesúticas. "A existência da cruz, como ideia e como objeto, no contexto religioso da tribo, é uma das primeiras coisas que despertam a atenção de quantos se põem a investigar o assunto que nos interessa aqui [relação entre a 'religião guarani' e o cristianismo][...]" escreveu Egon Schaden num artigo de 1982 (SCHADEN, 1982: 12).

O problema sobre a origem da cruz (se foi introduzida via jesuítas ou se já existia antes da colonização) ou sobre a influência do cristianismo no uso atual do objeto sintetizam toda uma maneira canônica pela qual a literatura guarani abordou, e ainda aborda ${ }^{7}$, o chiru. O presente trabalho busca desviar-se desse modo de abordagem, acessando a problemática kaiowa sobre o chiru de outra

\footnotetext{
${ }^{6}$ É comum ouvir a denominação Kaiowa-Guarani, referindo-se as duas populações (os Kaiowa, de um lado e os Guarani Nandeva, de outro) que, ainda que muito próximas geográfica e culturalmente, se reconhecem como distintas. Assim, ora tais povos se identificam conjuntamente, ora separadamente, dependendo do contexto de interação. Juntos, os Kaiowa e Guarani totalizam quase 44 mil pessoas. No caso do presente trabalho, refiro-me apenas aos Kaiowa, pois, do que sei, são aqueles que utilizam o chiru em suas práticas xamânicas (os Ñandeva não o fazem).

7 Um exemplo de trabalho recente que busca explorar as influências do cristianismo na cosmologia guarani é o artigo de Carlos Fausto "Se Deus fosse Jaguar: canibalismo e cristianismo entre os Guarani (séculos XVI-XX)" (2005). O texto começa reproduzindo as seguintes indagações sobre o kurusu ñeegatu que, segundo o autor, persistem desde os cronistas jesuítas: "Como devemos entender a afirmação dos Kaiová de que são os filhos da 'cruz da boa palavra', aqueles que brotaram da 'base espumante da cruz' (Chamorro 1995: 60)? Qual o estatuto dessa autodefinição e como interpretá-la? Trata-se de um arremedo de cristianismo mal compreendido ou de um mero verniz sob o qual se esconde uma verdadeira religião indígena?” (FAUSTO, 2005: 385).
} 
maneira. Isso porque presumimos que, ainda que a hipotética origem colonial da cruz seja um tema plausível, ela não assume relevo nos usos kaiowa do chiru, mesmo quando o que está em jogo é a relação desse objeto com o mundo nãoindígena. Um exemplo disso está contido no artigo "A trajetória dos chiru na construção da tradição de conhecimento kaiowa”, do antropólogo Fábio Mura. Dentre vários outros pontos, o trabalho evidencia que, menos do que a gênese cristã da cruz, o que tem preocupado os xamãs kaiowa atualmente é o problema de como cuidar dos chiru e transmiti-los adiante no contexto de vida imposto pelos brancos depois da expulsão dos tekoha (contexto que inclui a influência do missionarismo católico e protestante) (MURA, 2010: 138-142).

Em outras palavras, é como se a hipótese da gênese cristã da cruz indígena não fizesse jus às preocupações localmente mais relevantes. Não se trata, pois, de uma boa porta de entrada para o assunto; partindo-se desse equívoco, o risco é que a análise torne-se pouco produtiva. Quando digo "equívoco" e "produtividade" tenho em mente as perspectivas epistêmicas que supõem que, na base do fazer antropológico, estão enganos ou equivocações produtivas (SAHLINS, 2008 [1981]; ALBERT, 1992; VIVEIROS DE CASTRO, 2004). A disciplina estaria fundamentada numa disjunção entre as premissas coloniais e as premissas nativas, uma espécie de mal entendido que, ao modo de uma cismogênese batesoniana, em vez de gerar incomunicabilidade, é justamente o que possibilita e dá contorno à interação mutua (BATESON, 2008 [1936]). Diante dessa dessimetria de base, o objetivo não seria solucionar o equívoco, ou seja, não seria buscar uma síntese ou "fusão de horizontes", mas sim assumi-lo, evidenciando as diferenças e desigualdades de pressupostos em jogo e, mais do que isso, fazendo os pressupostos nativos relativizarem e transformarem os pressupostos analíticos dominantes (VIVEIROS DE CASTRO, 2002). Em outras palavras, há que se construir uma economia etnográfica na qual a teoria nativa transgrida certas dualidades axiomáticas de nosso pensamento e prática (HOLBRAAD, 2007: 191). A meu ver, questionar se o chiru é ou não originalmente cristão é um equívoco, como qualquer outra pressuposição ou hipótese antropológica, mas um equívoco pouco produtivo, já que talvez não nos leve a fundo o suficiente, nem nos faça ser afetados e transformados por aquilo que os Kaiowa pensam a respeito.

Em vez disso, proponho adentrar a seara por meio de outra via de acesso. Como se tentará evidenciar adiante, quase toda exegese kaiowa sobre o tema parece sublinhar a força, poder ou potência inerente à insígnia. A impressão é de haver, inclusive, um certo cuidado, respeito e até mesmo temor quando os rezadores tocam no assunto; são frequente as advertências dos xamãs contra um possível desdém ou ingenuidade dos não-indígenas para com aquilo que presumem ser um objeto qualquer ou algo confuso e ininteligível. Abordar antropologicamente este mote de reflexão indígena implica, pois, estar às voltas com uma equivocação particular ligada à tendência de que o pensamento dos brancos subestime a potência do chiru e sua capacidade imediatamente política de agir no mundo, seja porque ele aparece aos olhos estrangeiros como um simples "objeto", seja porque é entendido como uma "palavra" ou "ideia" pouco precisa. Valendome das reflexões de Evelyn Zea (2008: 66) sobre teorias e práticas de tradução dos Wai Wai, sugiro que o foco das especulações kaiowa no diálogo com os brancos sobre o chiru implique menos uma questão de gênese e mais uma questão de genitivo, de modo de relacionar, aproximar ou articular dois elementos; ou seja, o que vem etnograficamente a tona não é se o cristianismo trouxe ou não a cruz, 
mas sim certo espanto pelo fato dos brancos não terem dimensão da maneira e da intensidade com que o chiru se relaciona com o mundo ${ }^{8}$.

O texto que segue estará dividido em duas partes, cada qual explorando um desses aspectos do mal-entendido analítico, num caso envolvendo a abordagem do chiru como "objeto" e noutro caso a tradução do chiru como "conceito". Verse-á que tais traduções não são totalmente precisas, pois o chiru é bem mais do que um mero "objeto" ou "conceito"; tais abordagens funcionam como "vagas ideias iniciais" (VIVEIROS DE CASTRO, 2002: 122) que balizam um primeiro e provisório olhar sobre assunto. O intuito geral é mostrar que uma mirada atenta ao chiru e ao poder que o pensamento kaiowa nele reconhece demanda uma revisão de nossos pressupostos canônicos sobre a esfera "política" calcados que estão em dicotomias como sujeito-objeto ou objeto-conceito.

\section{Tecnologia cosmopolítica para filiação intensiva}

Os chiru são cruzes de madeira que variam da altura de alguns centímetros até um metro e meio aproximadamente (MURA, 2010: 121; MORAIS, 2017: 321). $\mathrm{O}$ esmero com que eles são tratados pelos rezadores pode deixar um observador ocasional intrigado. Porque tanto zelo e cautela por um simples objeto? "Os nãokaiowá acham que o xiru é apenas um pedaço de pau" queixou-se um xamã da aldeia Sucuru'i ao historiador kaiowa Izaque João (JOÃO, 2011: 27). Em visita a aldeias kaiowa nos anos 1950, Schaden observou alguns chiru adornados com as mesmas vestes rituais dos rezadores (pochito) e se perguntou: haveria no ato "uma personificação da cruz?” (SCHADEN, 1974 [1954]: 34). O antropólogo lançou a pergunta sem nunca tê-la investigado etnograficamente, mas, caso a tivesse dirigido a qualquer um dos seus interlocutores, de certo teria uma resposta afirmativa. "O ñanderu Jorge da Silva de Dourados explicou que os xiru 'para nós é uma pessoa... para vocês (não indígenas) pode parecer só um pedaço de pau à toa, mas para nós não é assim, ele tem muito valor, nós precisamos dele pra tudo"” (MACHADO \& PEREIRA, prelo: 126).

A rezadora Floriza de Souza mostrou-me pela primeira vez os chiru dos quais cuida quando contava da necessidade de reconstruir sua casa de reza. De seus dizeres, sobressaiu-se uma preocupação em particular. Havia algum tempo que o sapé que recobre as paredes e o teto da construção vinha se desgastando, deixando algumas frestas indesejadas, por onde a água da chuva e a ventania podiam entrar. O problema maior, neste caso, era que o lugar deixasse de ser adequado para guardar os chiru. O chiru não pode se molhar, dizia a rezadora, pois o mundo inteiro se molhará. Se não está em uma das mãos dos rezadores para algum procedimento especial, o chiru deve ficar assentado dentro das casas de reza ou então perto da rede de seus donos.

Além de não deixá-lo exposto, o rezador deve travar com o chiru um "diálogo quase cotidiano” (MURA, 2010: 137). O chiru se alimenta de rezas (porahei,

\footnotetext{
${ }^{8}$ Não que o conhecimento envolto no chiru exclua indagações e assertivas sobre sua origem. Como se verá abaixo, existem complexas narrativas a respeito, mas todas elas parecem categoricamente atribuir a gênese ao grande demiurgo (Ñanderuvusu) e à substância motriz (jasuka) que, mutuamente, criam o mundo e os Kaiowa, e não aos brancos, que surgem noutro canto e a partir de outra substância (tanemby). Perguntar-se sobre a relação entre a origem das coisas e o cristianismo também parece ser alvo de diversas reflexões ameríndias, inclusive entre povos guarani; contudo, seguindo os trabalhos de Gallois (2012) e Pierri (2014) a respeito, creio ser necessário acautelar-se na etnografia, fazendo as especulações analíticas seguirem, ponto a ponto, as especulações nativas, os modos indígenas de aproximar e distanciar, conectar e desconectar sistemas indígenas e sistemas não-indígenas. Com efeito, e insistindo uma última vez nesse ponto, investir, tal qual a literatura guarani tantas vezes fez, na hipótese da origem cristã da cruz é algo que encontra pouco ou nenhum lastro naquilo que os Kaiowa falam a respeito, o que implica o risco de passar ao largo do que é relevante para a vida dessas pessoas.
} 
cantos-danças) e, por isso, todos os dias, o rezador canta para agradá-lo e mantêlo frio (roy). Caso não caso seja alimentado, ele fica quente ( $h a k u$ ) e furioso. A qualidade sensível haku-roy parece ser central para os Kaiowa no que tange à avaliação dos comportamentos e estado de ânimo das pessoas. Segundo Lauriene Seraguza, haku pode ser pensado "como um estado que comporta a potência da superabundância, da alteridade, o momento que permite a emergência do excesso na vida social Kaiowa e Guarani” (SERAGUZA, 2013: 92-93). A ñandesy Floriza falou-me certa vez que "chiru [...] não pode passar 20 dias sem rezar para ele não. Ele já começa incomodar. Igual o gatinho. Fica miando, miando. Tem que agradar ele, se não, não dá”. A irritação que começa com um gato logo pode evoluir para uma onça e aí as consequências serão catastróficas. A ferocidade desse animal pode devastar a terra.

Pelo que depreendi do que me disseram Jorge da Silva e Floriza de Souza, os efeitos destrutivos do chiru variam conforme o elemento causador de sua irritação: a depender da falta de cuidado (caso seja molhado, abandonado, esquentado com uma reza, etc), o chiru pode causar tempestades, grandes ventanias, terremotos e ataque de animais. Neste último caso, parece haver algo como uma "jaguarização" do comportamento de diferentes espécies animais: "ataques de enxames de abelhas, de onças ou maior ocorrência de acidentes com víboras são facilmente associados ao descontentamento dos xiru" (MACHADO \& PEREIRA, prelo: 127). Por outro lado, quando está frio e sereno, o chiru é de grande valia aos rezadores, um poderoso instrumento. Ele torna-se algo próximo de um aliado e confessor.

Para manter o xiru como aliado, o xamã deve sempre proferir as rezas que sustentam a proximidade entre eles. Deve conversar constantemente com ele, expondo os problemas vivenciados na comunidade, explicar quem são os visitantes que recebe em sua casa e aconselhar-se sobre os problemas enfrentados no dia a dia dos parentes. Nesse sentido, o xiru é uma espécie de confessor. (MACHADO \& PEREIRA, prelo: 126)

O chiru serve para batizar colheitas, batizar crianças, curar doenças, entre outras incumbências dos xamãs no cuidado aos seus. A água utilizada para esfriar um chiru serve de remédio para vários tipos de doença segundo Izaque João (JOÃO, 2011: 51). O batismo, ou assentamento da palavra-alma (ñe'e), ação decisiva na vida kaiowa, depende do chiru para acontecer, tal qual se pode verificar no relato do antropólogo kaiowa Tonico Benites.

\footnotetext{
Minha mãe e meu pai narram ainda que com um mês de vida passei por um ritual de assentamento de nome/alma no corpo - mitã mongarai. Isto é, fui "batizado" por um rezador - ñanderu - de confiança que já havia realizado diversos mitã mongaraí na minha família. Este ritual foi realizado durante a noite na casa deste ñanderu onde se encontravam os instrumentos requeridos para a realização do ritual, como o xiru marangatu. Pode-se dizer que o nome/alma de uma pessoa - ñe e ayvu réra - só é trazido na presença desses instrumentos e após convocação repetida por meio da realização de cantos e rezas especiais - ñengary ayvu reruhá - para assentar a alma no corpo da pessoa. Assim, na madrugada, após longas horas de cantos e rezas de evocação do nome/alma, coordenado pelo ñanderu e pelo seu auxiliar - yvyra'ija -, e acompanhado do meu pai e de outros casais convidados, foi recepcionado o meu nome/alma - che ayvu réra - sob a iluminação de uma vela feita de cera natural de abelha jataí jate $i$ araity. O meu nome/alma é Ava Vera Arandu que pode ser traduzido por Homem (Ava) Sábio (Arandu) Iluminado (Vera). (BENITES, 2014: 13-14)
}

Os rezadores obtém o chiru de diferentes maneiras. Alguns chiru são construídos e, nesse caso, é preciso fazer um delicado e potencialmente perigoso trabalho de transformação de um objeto em uma pessoa, o que envolve o esquentamento e posterior esfriamento da madeira (MURA, 2010: 136). Por outro lado, na maioria dos casos, os chiru são herdados, seja através de reuniões e acordos 
dentro das famílias extensas nas quais se decide quem será o novo portador, seja através de visões e sonhos que fazem o xamã localizar a dádiva enviada pelos deuses. Em ambos os casos em que a cruz é legada, parece pesar em grande medida a vontade do chiru - é ele quem escolhe seu novo dono.

Em suma, chiru é um objeto, uma cruz de madeira que serve a vários propósitos, portanto também uma ferramenta componente do equipamento xamânico. Ao mesmo tempo, o chiru é pessoa: dele você cuida, alimenta, conversa, veste, agrada. E, ademais, alguém com imensas capacidades, pois ele cura doenças, nomina crianças, batiza colheitas, provoca desastres ambientais. Este ente superpoderoso parece, pois, obliterar nossa costumeira dicotomia entre objeto e sujeito, sendo necessário repensar nossas bases de pensamento para compreender exatamente sua natureza e função.

Para tanto, propomos recorrer a uma perspectiva da teoria social inaugurada por Gilles Deleuze e Félix Guattari na obra O Anti-Édipo (2010 [1972]). No célebre capítulo III do livro, os autores produzem um comentário sobre uma parcela da narrativa de origem Dogon (povo da África Ocidental) transcrita por equipes de etnólogos franceses em meados do século XX (dentro os quais Germaine Dieterlen e Marcel Griaule). O fragmento remete aos atos do trickster Yurugu. No começo do mundo, há um ovo cósmico criado pelo deus Amma que contém duas placentas, cada qual com um gêmeo, que são os protótipos da humanidade. Um dos gêmeos, Yurugu, nasce intempestivamente e rouba uma parte da placenta para fazer outra terra que seria, segundo suas intenções, mais perfeita que o ovo cósmico. Tal intento dá errado e, com saudade de sua outra metade, Yurugu penetra a placenta produzindo um incesto primordial, pois a placenta é, ao mesmo tempo, sua mãe (posto ser uma substância matriz do mundo), sua irmã (pois é criada pelo seu pai Amma) e em parte ele mesmo (pois ele se alimentava dela quando estava no ovo). Os seres do mundo atual, bem como a organização social dogon, baseada em linhagens, nasceriam das tentativas de corrigir as ações de Yurugu'.

Como notou Eduardo Viveiros de Castro, "o lugar que esse relato ocupa na argumentação geral [de $O$ Anti-Édipo] revela ser de grande importância teórica" (VIVEIROS DE CASTRO, 2010: 125). Ao longo do livro, os autores buscam delinear uma teoria do inconsciente psicanalítico e do mundo social descentrada da noção de representação simbólica. Um dos motes da obra é que "o inconsciente funciona como uma usina e não como um teatro (questão de produção, e não de representação)" (DELEUZE \& GUATTARI, 1995: 7). Do ponto de vista "edipiano", um mito de uma população tradicional, uma peça literária ou um sonho relatado numa clínica de psicanálise são encarados como encenações que expressam, linear ou dialeticamente, o nível da realidade propriamente (o inconsciente, a estrutura social, etc). Essa disjunção entre imaginário e real, porém, é recusada pelos autores em favor de outra distinção: o mito daria notícias de uma ordem que definem como intensiva, diferente da ordem extensiva na qual os Dogon vivem atualmente. $\mathrm{O}$ ato de Yurugu é, ao mesmo tempo, social e bio-cósmico, pois mistura um ser material (Yurugu) e uma substância vital energética (a placenta motriz que torna-se a terra); é também, simultaneamente, um ato de filiação e de aliança, pois Yurugu casa-se com alguém que é sua mãe, sua irmã e, em parte, si mesmo (DELEUZE \& GUATTARI, 2010 [1972]: 205). No estado de coisas atual, essas diferenças são dadas na forma de uma alternativa exclusiva, já que aliança e filiação, bem como a sociedade e a natureza definem-se por exclusão mutua -

9 Este breve resumo da narrativa dogon foi baseado na tradução livre que Denise Dias Barros (2004) realizou do relato de Germaine Dieterlen. 
hoje casar-se com uma irmã ou com uma placenta são considerados atos incestuosos ou transgressivos. Já no estado de coisas míticas, as diferenças pertencem ao regime lógico da síntese disjuntiva ou da disjunção inclusiva.

\begin{abstract}
E já sabemos o que é esta filiação intensiva, esta disjunção inclusiva na qual tudo se divide e na qual o mesmo ser está em todas as partes, de todos os lados, em todos os níveis, apenas com diferenças de intensidade. O mesmo ser incluso percorre sobre o corpo pleno distâncias indivisíveis e passa por todas as singularidades, por todas as intensidades de uma síntese que desliza e se reproduz [...] Podemos então compreender melhor por que o problema não consiste, de modo algum, em ir das filiações às alianças ou em concluir estas daquelas. O problema está em passar de uma ordem intensiva energética a um sistema extensivo, sistema que compreende, ao mesmo tempo, as alianças qualitativas e as filiações extensas (idem: 205).
\end{abstract}

Acrescenta-se ainda que o estado de coisas do começo do mundo não termina em absoluto: a ordem de relações intensivas ainda se faz presente como possibilidade, sendo uma virtualidade sempre pronta a se atualizar no mundo de agora. Isso fica evidente quando os autores formulam, num texto posterior, a ideia de uma aliança demoníaca, remetendo-se aos potenciais casamentos entre humanos e seres monstruosos relatadas por certas tradições xamânicas sudanesas (DELEUZE \& GUATTARI, 2012). A relação entre extensivo e intensivo é da ordem da síntese disjuntiva; a passagem do contínuo ao descontínuo, tal qual formulado por Lévi-Strauss, seria sempre, em alguma medida, reversível ${ }^{10}$. Nesse sentido, mesmo hoje, todo objeto de uma ação ou percepção é virtualmente um sujeito, sendo o mundo ainda povoado por "seres inclusos", tais quais o Yurugu, e atravessados por "influxos germinais", tais quais a placenta matriz do mundo. Ademais, a aliança ou a ancestralidade nunca restringem-se à dimensão mundana, estando a política e o parentesco espalhados por todo o cosmos.

"É em intensidade que é preciso interpretar tudo" (DELEUZE \& GUATTARI, 2010 [1972]: 210). Ler o chiru como um mero objeto implica ignorar as imensas capacidades e perigos envoltos em sua manipulação. Para aprofundar esse ponto, façamos um recuo às narrativas de origem kaiowa que, tal qual a narrativa dogon, oferecem testemunho de uma espécie de ontogênese filiativa, na qual os seres vão gerando-se por sucessivas relações de filiação ${ }^{11}$. O mundo é criado por uma divindade comumente designada por expressões que se referem à figura paterna, tais quais Ñandervusu (nosso grande pai) ou Ñanderamoi (Nosso Avô) (CHAMORRO, 2008: 130). Há também uma grande Ñandesy (Nossa Mãe) (em algumas versões criada pelo Ñanderuvusu, em outras, encontrada nalgum de seus adornos) que fica grávida, mas que, por suspeita de traição ou por alguma briga, é por ele abandonada. A mãe dá a luz a filhos gêmeos não-idênticos, Kuarahy e Jacy (Sol e Lua) que, em suas desventuras (vingança contra as onças que matam sua mãe, procura pelo pai ausente, intrigas contra o trickster $A \tilde{n} \tilde{a}$ ou Ke'yhum), vão tornando o mundo habitável (CHAMORRO, 2008: 132).

\footnotetext{
${ }^{10}$ A problemática do contínuo e do descontínuo no pensamento de Lévi-Strauss é vasta e atravessa diferentes momentos de sua obra. Para um escrutínio rigoroso da questão, conferir Lolli (2005). A menção a ela neste artigo mira, especificamente, as passagens das Mitológicas em que o tema é conectado com a relação entre natureza e cultura. Como observa Sztutman, os mitos contidos no primeiro volume O Cru e o Cozido em geral falam da passagem da época em que os animais eram gente (natureza, continuidade), para a época em que homens e animais perdem a comunicação entre si (cultura, descontinuidade), e os mitos contidos no segundo volume Do Mel às Cinzas falarão sobre a regressão ao primeiro estado de coisas. "As Mitológicas referem-se, em suma, a uma passagem da natureza para a cultura, mas que nunca se completa, podendo ser revertida" (SZTUTMAN, 2009: 4). Haveria uma espécie de paradoxo, uma tensão que não se soluciona pois, por um lado, a reversão é vista como caos, desordem (algo atestado por figuras perigosas como os venenos e os eclipses) e, por outro lado, a passagem é vista como tragédia, como lamento pela incomunicabilidade (algo que atesta a importância e desejabilidade do xamanismo e do tabaco como atividades mediadoras do que se separou) (IDEM).

${ }^{11}$ As semelhanças, no entanto, são apenas parciais, pois a narrativa dogon redundará na criação de ancestrais fundadores de linhagens rigidamente definidas que, ao que parece, chegam até aos ancestrais imediatos. A organização kaiowa em quase nada se aproxima desse modelo linhageiro e sua narrativa de origem possui outros desdobramentos.
} 
Antes, porém, havia jasuka, um elemento menos enfatizado pela literatura, que é pré-pessoal, no sentido de ser anterior à divisão em pessoas começada com o surgimento do criador (CHAMORRO, 2008: 123). O rezador Jorge da Silva traduziu-me jasuka certa vez como uma "espuma branca" ou "leite materno". É um "fluido vital" por vezes também associado à imagem de uma névoa branca, ou de uma flor. A literatura conta com outras traduções: "origem de tudo, até mesmo dos deuses" (Marcial Samaniego) "mãe universal” (Cadogan), "princípio de emanação" (Schaden) (CHAMORRO, 2008: 122-123). Alguns rezadores traçaram para Graciela Chamorro uma analogia entre jasuka e um motor.

\begin{abstract}
O kaguĩ [bebida tradicional feita de milho] é o primeiro sumo de Jasuka. Jasuka é para nós o que o motor é para os brancos; com a diferença que Jasuka é natural, não é feito. Ele serve para nos dar vida e nos recompor. Algumas pessoas são refeitas a tal ponto por Jasuka que não morrem, ficam novas outra vez, como uma criança de lábio recémperfurado. O kaguĩ, que é a expressão de Jasuka, é o nosso princípio, é ele que nos renova a todos (CHAMORRO, 2008: 126).
\end{abstract}

“O ser criador surge, nasce, descobre-se a partir da Substância Mãe e cresce mamando na flor, no seio de Jasuka" (CHAMORRO, 2008: 123-124). Também de jasuka, o criador faz o primeiro chiru, que servirá como um esteio ou sustentáculo para a criação da terra. No fragmento seguinte, Eliel Benites detalha a Bruno Morais o surgimento do chiru.

Primeiro ele fez descer a cruz, a cruz originária. O chiru principal, ele fez descer. Ou seja, ele desceu o chiru. E o chiru é o próprio Deus, que vem descendo pela cruz, vem descendo, e embaixo dela ele ficou como um grão de areia, como um inseto parado! Esse tempo que ele ficou adormecido, ninguém sabe quanto foi - agora a gente quer medir tudo, né? Mas ele ficou muito, ali, assim, adormecido. E um dia ele começou a desabrochar como uma flor, como uma metamorfose, como uma borboleta, e saiu dali o chiru como uma criança novinha. Então ele começou a dançar, e a cantar, porque ele dependia da dança, ele dependia do canto. O chiru se alimenta do canto. O chiru é o próprio ñe'e, a voz, o canto. E é por isso que ele foi dançando ao redor da cruz, primeiro engatinhando mas logo ele ficou maior, dançou de pé, se ergueu segurado na cruz. Cantava e dançava. (MORAIS, 2017: 326)

Quando retorna à morada celeste, Ñanderuvusu deixa o chiru para os humanos de modo a manter um canal de comunicação que era plenamente acessado por todos antes das trilhas que interligavam deuses e humanos serem fechadas agora só os rezadores fazem esse caminho (MURA, 2010: 134). Izaque João também comenta o surgimento do chiru em sua dissertação de mestrado:

\footnotetext{
De acordo com a lógica do Kaiowá, a terra foi criada a partir da substância do xiru (bastão sagrado), o jasuka. Segundo o xamã, no princípio da existência da terra, o nhanderu guasu entendeu que a terra necessitava ser sustentada pelo xiru. Desde então, o xiru ryapu guasu (divindade dona do xiru), com a sua inteligência, ordenou ao seu yvyra`ija um canto específico para cada fenômeno natural. Com essa exigência, o nhanderu guasu instituiu as regras relativas aos cantos referentes ao xiru e sua criação. Dessa forma, os Kaiowá entendem que os cantos compõem a própria estrutura do xiru ou kurusu e ele se expressa através dos cantos. Esse objeto é incorporado de perfeição, para servir de base de sustentação da terra. Porém, para o xiru se tornar um dos instrumentos fundamentais para equilibrar todas as espécies de fenômenos, é preciso ser alimentado pela reza, para continuamente retribuir de maneira adequada para os seres humanos. Portanto, a terra, na concepção kaiowá, é sustentada pelo xiru, que é o instrumento principal para se comunicar com os deuses. (JOÃO, 2011: 26)
}

O cosmos para os Kaiowa é concebido como uma sucessão de patamares nos quais um "xamã experiente transita tanto na verticalidade quanto na horizontalidade [...]” (PEREIRA, 2004: 239). A terra habitada pelos Kaiowa é como que um ponto intermediário entre um patamar subterrâneo, lugar de seres noturnos, ligado à escuridão e corrupção, e patamares celestiais, morada dos deuses, ligados 
à luminosidade e perfeição/maturação (aguyje) (IDEM: 242-243). É para lá que os Kaiowa visam ascender. Lançando mão das rezas, do chiru e de outros instrumentos, os rezadores transitam e se comunicam com as divindades e demais seres cósmicos. Comunicação e espacialidade estão diretamente relacionadas, de tal modo que agir aqui implica dizer (cantar, rezar) e transitar: "Os cantos são meios para visualizar o caminho iluminado (tape rendy) que leva à morada dos deuses para adquirir conhecimento na condução do seu povo" (E. BENITES, 2014: 38). Certa vez, a rezadora Floriza de Souza comparou o chiru a um aparelho de geolocalização por satélite (GPS).

\begin{abstract}
Tem com ele aparelho. Ita vera [pedra iluminada ou resplandescente]. Onde a gente vai leva isso daí não acontece nada. Isso daí brilha o caminho da pessoa, aonde você vai não acontece nada. E com ele vem a reza. É igual o que você usa no carro, o GPS. Aonde você vai, aonde não pode ir, você não pode entrar ali não, porque você vai mal. Tem que seguir aonde é correto. É assim. Para isso, a gente aonde vai, leva. Eu não deixo não.
\end{abstract}

Nada de fabulação, fetichismo ou simples simbolismo: para compreender a potência do chiru é preciso assumir um ponto vista intensivo, deslocando as usuais premissas extensivas que colocam sujeito e objeto, humanos e não-humanos (animais, espíritos, deuses) como antinomias. Tal como nos mostra Bruno Latour, a recusa em encarar tais instrumentos como verdadeiras tecnologias é efeito de toda uma arquitetura intelectual e política moderna, um arranjo ou constituição que esvazia o poder e capacidade de outros povos e seres em favor de seus próprios modos de pensar e produzir (LATOUR 1994 [1991]). Diante de objetos como o chiru, os ditos modernos costumam impor "escolhas cominatórias", questionamentos que obrigam a decidir por classificações exclusivamente opostas: ou bem é um objeto, ou bem é um sujeito; ou bem é construído, ou bem é dado; ou bem é social/político ou bem é natural/cósmico (LATOUR, 2002 [1996]: 21-22). Aparelhos como o chiru, porém, escapam a tais alternativas exclusivas, uma vez que atravessam as dimensões da natureza e da sociedade, do cosmos e da política $^{12}$. Confeccionado da matriz geradora jasuka, um influxo germinal para o qual os Kaiowa visam retornar, o chiru consiste, pois, numa poderosa tecnologia cosmopolítica para resplandecer as caminhadas cósmicas dos rezadores e atualizar a potência filiativa da relação com seus demiurgos. Do mesmo modo, da tradução do chiru como uma tecnologia, tal qual feito por muitos dos próprios ñanderu e ñandesy kaiowa, não se deve depreender qualquer tipo de passividade, pois se trata também de um sujeito: como vimos o chiru é também pessoa, temperamental e com altas capacidades transformativas, que podem o fazer passar de um confessor colaborativo, quando está frio (roy), a um jaguar incontrolável quando está quente (haku).

\title{
Operador ontológico
}

Ainda que chiru tenha sido a palavra que mais ouvi em campo e li na bibliografia, há outros termos para designá-lo: kurusu, yvyra jehovasa (SCHADEN, 1982: 13). Por outro lado, é preciso observar também que a palavra chiru não designa apenas a cruz de madeira, constituindo um termo bastante polissêmico.

\footnotetext{
${ }^{12} \mathrm{E}$ isso vale para outros tantos divisores e dicotomias, tais como mostram o conjunto de novas vertentes antropológicas sobre o tema dos objetos que surgem depois dos anos 1950 (FARIAS, 2015: 62). Dentro dessas tendências, pode-se destacar em especial aquelas que surgem na antropologia britânica durante os anos 1990, com autores como Alfred Gell e Marilyn Strathern (IDEM: 63). Ainda que o presente artigo não tenha produzido uma aproximação entre a problemática do chiru e tal tradição de estudos, ela certamente pode ser proficuamente experimentada em esforços futuros.
} 
Caso empreendêssemos a feitura de um verbete do chiru numa enciclopédia ou dicionário, poderíamos listar os seguintes sentidos:

1. Pode ser traduzido como "meu pai", pois é a composição de dois termos, "chi", uma variação do pronome possessivo da primeira pessoa do singular (che), e "ru",que designa figura paterna. (VIETTA, 2007: 157)

2. É a cruz ritual de madeira cuidada pelos rezadores. Como dito acima, nessa acepção é sinônimo de kurusu, Pode também ser usado como uma categoria englobante para designar todos os outros objetos utilizados pelo xamã. (MACHADO \& PEREIRA, prelo: 120)

3. É um termo para designar as figuras que o vocabulário antropológico corrente chama de xamãs. Para tanto, os kaiowa também se valem de outros termos: ñanderu ("nosso pai"), hechakara, rezador, paí, cacique. (VIETTA, 2007: 460)

4. Em diversas apreciações kaiowa sobre a configuração do cosmos, constitui uma espécie de base ou esteio da terra habitada pelos humanos. (JOÃO, 2011: 27)

5. É usado para se referir à divindade criadora do mundo, que hoje habita o mais alto patamar celeste. (CHAMORRO, 2008: 153)

Talvez haja outros significados que tenham me escapado. O fato é que essa variação no sentido da palavra certamente pode causar confusão a um ouvinte desavisado, um karai $^{13}$ pouco versado na filosofia kaiowa que, quando ouvir falar do chiru, pode não se saber bem qual objeto semântico está sendo referido, o pai, o rezador, o esteio, a divindade, a cruz ritual... Ele poderia supor, neste sentido, que, por designar muita coisa, o chiru é um conceito confuso, pouco preciso e, por isso, pouco operativo. Poderia também atribuir essa polissemia a uma simples coincidência terminológica, uma homonímia arbitrária como acontece com tantas palavras. Nem uma nem outra das suposições, porém, creio ser correta. Em ambos os casos, corre-se o risco de, mais uma vez, recair numa interpretação que não leva em conta o quanto o chiru é algo potente e carregado de valor para os Kaiowa. As considerações seguintes, tecidas por Eliel Benites em entrevista para o antropólogo Bruno Morais, nos dão indícios de que o emprego do termo chiru não é inexato nem arbitrário.

\begin{abstract}
Para nós, tudo é sempre dois: o irmão maior e o irmão menor, o Sol e a Lua, Kuarahy e Jasy. Todo o equilíbrio da natureza, toda a ecologia, a separação da terra e da água, tudo isso é sustentado em um esteio chamado chiru, o elemento sustentador de toda a existência. É o chiru, que é o próprio Ñanderu, que na visão indígena está no centro da terra. Outros rezadores dizem que está no centro do mar, que é uma outra forma de se dizer a mesma coisa: ele é o que divide a água e a terra, e também o céu e a terra. Todas essas divisões são sustentadas no equilíbrio do chiru, na distância dos pontos cardeais. (MORAIS, 2017: 326-327)
\end{abstract}

O chiru é um equilíbrio que sustenta tudo, um suporte para organização das diferenças em forma de cruz. "Nós também somos cruzes” indicou E. Benites na mesma entrevista, referindo-se à forma que o corpo assume quando alguém abre os braços. Seríamos uma espécie de armação em cruz que sustenta o corpo e a alma-palavra ( $\tilde{n} e$ 'e) a qual, vinda do céu, se assentaria no cruzamento entre o eixo dos braços e o eixo da coluna cervical - ponto que coincide com a garganta, que é a sede da voz, da capacidade de fala (IDEM: 327). Não à toa existe a expressão kurusu kue, imagem utilizada por alguns para designar a morte de alguém, a cruz que se desarmou (CHAMORRO, 2008: 350) ${ }^{14}$. Ademais, na dimensão

${ }^{13}$ Karai é o vocábulo a partir do qual os Kaiowa se referem aos brancos.

${ }_{14}$ A autora lista também as expressões apyka kue (pessoa "torna-se um banco que já foi acento da palavra") (CHAMORRO, 2008: 347) e mbaraka kue ("na pessoa que falece, emudece a voz de Deus" (IDEM: 350), ambas também se utilizando dos objetos xamânicos para indicar a morte de uma pessoa. 
interpessoal, como vimos, o chiru é a pessoa do xamã que entrecruza em si diferentes dimensões: de um lado, os planos terreno e extraterreno, sendo responsável pelo diálogo entre divindades e a humanidade (PEREIRA, 2004: 239); de outro, as temporalidades do passado e do presente, uma espécie de ponte entre seu auxiliar mais jovem (yvyra’ija) e os rezadores mais antigos (hechakara) que o capacitaram para a função (VIETTA, 2007: 460).

O chiru procede a divisões também no plano do espaço. Ele é o pilar cruzado do universo. Jorge da Silva disse-me certa vez que o "planeta" é uma grande bacia (ña'e guasu) que se mantém acima do oceano equilibrando-se em duas imensas flechas cruzadas. O equilíbrio é tênue, sendo necessário sempre rezar para não deixar a bacia tombar e, consequentemente, para evitar um dilúvio trágico. $\mathrm{O}$ chiru nesse caso separa terra e água. Ao mesmo tempo, como se depreende dos dizeres de E. Benites, o chiru funciona como uma referência para os pontos cardiais, correspondendo ao entrecruzamento entre os eixos formados pelo sentido leste-oeste e o eixo norte-sul. A casa de reza, por exemplo, é construída rigorosamente segundo estes eixos: a construção começa pelo lado nascente do sol, onde ficará a frente da casa, a entrada principal, e segue o sentido poente do sol; a cumeeira fica no sentido norte-sul; muitas das casas contam também com entradas laterais (no norte e no sul) (PEREIRA, 2004: 245-246).

O chiru é operativo também no plano das divindades. O rezador Jorge da Silva relatou-me que, quando as pessoas morrem, seu ñe'egue (alma-palavra que já se foi) sobe por uma estrada iluminada, tape rendy, um feixe luminoso que é como uma escada para os brancos, e que, em vida, apenas os rezadores podem ver, pois não tem o olho sujo (resa ky'a). Ao terminarem de subir a estrada, chegam na morada celeste, arajepota (tempo-espaço da transformação), onde nunca faz noite, e o tempo passa muito mais devagar que na terra. Tal dimensão tem a forma de uma oka guasu, uma grande casa de reza. Uma divindade auxiliar do criador (yvyra'ija) que fica cuidando da entrada da casa recebe o ne'e, coloca sobre ele adornos, convida-o para cantar e dançar em volta do yvyra’i e o conduz para ao Chiru ambape, a divindade principal, o verdadeiro pai de todos. A distinção operada pelo chiru no plano social se reproduz no plano celestial: o deus principal está para as divindades auxiliares assim como o rezador está para um yvyrai’ija.

Apenas por estas breves considerações, que de certo constituem uma parcela ínfima e simplificada das inúmeras e complexas exegeses kaiowa sobre o assunto, pode-se perceber a força metafórica e até mesmo poética da figura do chiru. Poder-se-ia concluir, pois, que o chiru é um eficaz operador simbólico, produzindo metáforas morfológicas, sociológicas, cosmográficas e teológicas. Contudo, escutando com atenção os dizeres acima, percebe-se que isso não é tudo. Eliel Benites indicou que o chiru é o ñanderu criador. Isso fica ainda mais patente numa consideração transcrita na seção anterior, quando este pesquisador discorreu sobre o papel do chiru na criação do mundo. Ele diz que "o chiru é o próprio Deus, que vem descendo pela cruz" e mais adiante que "o chiru se alimenta do canto. O chiru é o próprio ñe'e, a voz, o canto” (MORAIS, 2017: 326). O chiru é simultaneamente o esteio através do qual o criador faz a terra e é o próprio criador (e é aquilo do que se alimenta). Mais acima, foi mencionado que a casa de reza dos xamãs é disposta da mesma forma que a casa de reza das divindades. A partir de diálogo com rezadores, Levi Marques Pereira, explica que essa disposição não é algo aleatoriamente feito pelos construtores das casas, mas sim observada por eles nas viagens xamânicas à casa de reza celestial (PEREIRA, 2004: 246). Assim, ainda que um caso de mimetização, trata-se, não de um exercício de pura 
introspeção lógica, mas de reprodução de algo real, que se testemunhou de fato. Além disso, a própria divindade criadora, já referida na seção anterior, é um chiru, o kurusu ñeengatu, a cruz da boa palavra. Tal como explicou a família Turiba para Graciela Chamorro, o chiru é a intersecção entre as palavras das demais divindades, algo como uma central telefônica, um terminal de comunicação que, recebendo em si as diferentes linhas, ordena a ação e competência de cada membro do sistema (CHAMORRO, 2008: 153). O Ñanderuvusu é cruz na medida em que é atravessado pelo caminho dos deuses auxiliares; é uma espécie de ser cruzado, que comanda os outros a partir dessa matriz que tem em si.

\begin{abstract}
O xiru, que se encontra na residência do xamã, é o mesmo que sustenta a terra, dandolhe equilíbrio. Então, se o rezador parar de cantar, o nhanderu guasu movimenta o xiru, deslocando-o levemente, causando um tremor de terra, chamado kaja'a nheoepenha, ou outros fenômenos, como terremotos e maremotos. Por isso, o xiru tem sempre o seu lugar certo na residência do xamã. (JOÃO, 2011: 27)
\end{abstract}

A assertiva acima de Izaque João remete aos cuidados com o chiru descritos na seção passada. Assim como as considerações de Jorge da Silva sobre a grande bacia do mundo, o historiador kaiowa mostra a razão pela qual deixar de alimentar o chiru é tão perigoso. Existe uma continuidade real entre o sustentáculo da terra e o chiru da casa do rezador e, por isso, descuidar do segundo gera efeitos catastróficos generalizados (terremoto num caso, dilúvio no outro). Tendo em conta também a continuidade entre o grande criador e o chiru kurusu, pode-se aferir que a irritação do segundo atinge diretamente o primeiro, o que constitui outra explicação para os cataclismas. O equilíbrio entre diferenças proporcionado pelo chiru, portanto, não é apenas simbólico na acepção do termo que se opõem à realidade "literal", pois, quando ameaçado, pode gerar efeitos concretos no mundo.

O chiru é ao mesmo tempo muita coisa, e coisas que costumamos considerar como mutuamente excludentes, incompatíveis: é o aparelho de criação do universo e, ao mesmo tempo, o ser que o cria; é pessoa, fundamento, objeto, divindade; está, simultaneamente, nas mãos do rezador, no centro da terra e na casa de reza celestial. Do ponto de vista da Antropologia, mais uma vez, o chiru revelase extremamente potente, colocando em xeque, além da dualidade objeto-sujeito, também outro de nossos axiomas, a distinção objeto(coisa)-conceito.

Há tempos que a complexidade de conceitos como o chiru tem desafiado a imaginação antropológica. No texto "The Power Of Powder. Multiplicity and motion in the divinatory cosmology of Cuban Ifá (or mana, again)" (2007), Martin Holbraad delineia uma breve genealogia do desconcerto antropológico diante de tais categorias nativas. Os conceitos tipo-mana, segundo o autor, referindo-se à célebre noção melanésia, inquietaram diferentes autores e correntes de pensamento, sendo o estruturalismo de Lévi-Strauss uma delas.

\footnotetext{
Assim se explicam as antinomias, aparentemente insolúveis, ligadas a essa noção, que tanto impressionaram os etnógrafos e que Mauss evidenciou: força e ação; qualidade e estado; substantivo, adjetivo e verbo ao mesmo tempo; abstrata e concreta; onipresente e localizada. E, de fato, o mana é tudo isso ao mesmo tempo; mas não é assim, precisamente, porque ele não é nada disso? Porque ele é simples forma ou, mais exatamente, símbolo em estado puro, portanto suscetível de assumir qualquer conteúdo simbólico? (LÉVI-STRAUSS, 2003: 43)
}

O mana seria, para Lévi-Strauss uma pura forma, um "significante flutuante" porque ele desliza ou flutua sobre diferentes significados. Não se trata, pois, de uma confusão ou pobreza vocabular dos povos que o utilizam. Pelo contrário: para o autor francês, a natureza do mana é justamente ser operativo em termos 
simbólicos ou intelectuais e sua função exclusiva é correlacionar significados, produzir relações entre um sentido e outro. Donde residiria sua força conceitual, o atrativo que ele exerce tanto para as populações nativas quanto para os antropólogos. Contudo, como sustenta Holbraad no texto acima citado, o mana persiste desafiando a solução levi-straussiana, pois, como vimos, há mais do que isso em enunciados do gênero: o conceito não representa simplesmente diferentes coisas; ele é, de fato, essas coisas diferentes, ao mesmo tempo, produzindo transformações em cada referente que relaciona. Qualificar o mana como "simbólico" ou puramente "lógico" acaba por aprisionar o pensamento nativo numa camisa de força teórica, ou, nos termos de Latour (2002 [1996]), numa "escolha cominatória" duplo-vinculante entre representação intelectual e ação efetiva ou, mais precisamente, entre conceitos/símbolos que representam a coisa e ações/forças que agem sobre a coisa.

Com base no conceito de aché (segundo o autor uma espécie de primo afrocubano do mana) (HOLBRAAD, 2007: 201), Holbraad produz uma conceitualização alternativa que busca escapar desse armadilha dicotômica. Nas práticas do Ifá, aché designa a faculdade ou poder da adivinhação e o pó utilizado nas cerimônias para tanto (idem: 202). O aché é o material responsável por tornar imanente as divindades transcendentes (oddu), fazendo-as se manifestar durante a adivinhação - o processo todo é aché. As divindades falam através do pó, deixam marcas nele. Ao mesmo tempo, dizem os babalaos, tais índices não são meras representações, mas as próprias divindades (IDEM: 203). As divindades são feitas em sua imanentização e, nesse sentido, a propriedade material do pó não pode ser menosprezada, pois tal operação depende intrinsecamente da motilidade dessa "coisa", sua capacidade de mover-se, o fato de ser pulverizado em incontáveis partículas (IDEM: 208). O pó, assim, é imediatamente objeto e conceito, força e forma, política e intelectualidade; sua materialidade é, de saída, abstrata e, inversamente, sua abstração transforma a realidade. Nesse sentido, aché não seria um significante flutuante, mas sim um ser flutuante, um ser movente, um motor de operações político-ontológicas capazes de trazer os oddu ausentes para a presença efetiva (IDEM: 207).

Nestes termos, creio que o chiru também pode ser qualificado como um ser movente, um operador, não apenas lógico, mas, sobretudo ontológico. Sua capacidade de equilibrar e gerar diferenças na forma de cruz organiza e dá existência as coisas do mundo, ou seja, é simultaneamente intelectual e material, teórica e política. "Nos marcos desse universo, os conceitos deslizam-se entre si", indicou Bruno Morais (MORAIS, 2017: 324), e essa impressão parece ser especialmente válida para o chiru. Ele arquiteta as casas de reza, sustenta o planeta, arma o corpo e a alma das pessoas, produz uma conjunção dos seres divinos fazendo existir a divindade principal, a cruz da boa palavra. Mais uma vez não se trata de simples simbolismo: não alimentar o chiru com rezas, por exemplo, gera imensos terremotos e inundações, pois a cruz do rezador é a mesma que está no centro do universo, que, por sua vez, é a própria kurusu ñeengatu. A condição para entender assertivas como esta é produzirmos uma virada em nossos pressupostos tradicionais de como o mundo funciona, admitindo que estamos de fato diante de outro terreno metafísico, de outra ontologia. A separação radical entre representação (conceito, palavras, abstrações) e realidade (objetos, coisas, concretudes) não opera na filosofia kaiowa, que pensa e pratica esta relação de outro modo. Índice mais forte disso talvez seja o complexo conceito de alma-palavra diversas vezes referido até aqui: ñe'e é o princípio que anima uma pessoa e, simultaneamente, sua capacidade de fala, sua linguagem. Ou seja, a essência das pessoas é 
sua própria capacidade de expressão; algo existe na medida em que diz. Aquilo que a filosofia ocidental cunhou como virada linguística talvez seja um preceito banal para os Kaiowa: a eficácia das palavas é algo dado, autoevidente, e a centralidade que os cantos e rezas assumem no xamanismo aponta justamente para a materialidade da linguagem, seu caráter eminentemente ontológico. No caso do diálogo com o chiru, vimos como a reza é um verdadeiro alimento que nutre seu ser e o potencializa como veículo dos xamãs nas viagens pelo cosmos. Em torno desse canto, haverá todo um investimento estético que, longe de ser meramente superficial, representativo ou decorativo, determinará sua eficácia e natureza na relação com o objeto/objetivo para o qual ele se dirige. "Rezar é tornar-se palavra (ñembo'e)" (CHAMORRO, 2008: 153). As coisas existem na medida em que são postas em comunicação.

Recebido em 17 de setembro de 2018.

Aprovado em 17 de abril de 2019.

\section{Referências}

ALBERT, Bruce. A fumaça do metal: história e representações do contato entre os Yanomami. Anuário Antropológico. Brasília, 1992, 89: 151-189.

BARROS, Denise. Itinerários da loucura em territórios Dogon. Rio de Janeiro, Editora FIOCRUZ, 2004.

BATESON, Gregory. Naven: um exame dos problemas sugeridos por um retrato compósito da cultura de uma tribo da Nova Guiné, desenhados a partir de três perspectivas. São Paulo, Edusp, 2008 [1936].

BENITES, Eliel. Oguata Pyahu (uma nova caminhada) no processo de desconstrução e construção da educação escolar indígena da reserva indígena Te'ýiku. Dissertação de Mestrado em Desenvolvimento Local, Universidade Católica Dom Bosco, 2014.

BENITES, Tonico. Rojeroky hina ha roike jevy tekohape (Rezando e lutando): o movimento histórico dos Aty Guasu dos Ava Kaiowa e dos Ava Guarani pela recuperação de seus tekoha. Tese de Doutorado em Antropologia Social, Museu Nacional, Universidade Federal do Rio de Janeiro, 2014.

CHAMORRO, Graciela. Terra Madura, yvy araguyje: fundamento da palavra guarani. Dourados, Editora UFGD, 2008.

DELEUZE, Gilles \& GUATTARI, Félix. Prefácio para a Edição Italiana. In: DELEUZE, Gilles \& GUATTARI, Félix. Mil Platôs - v. 1. São Paulo, Editora 34, 1995, pp. 7-9. . O Anti-Édipo. São Paulo, Editora 34, 2010 [1972].

. Devir-Intenso, Devir-Animal, Devir-Imperceptível. In: DELEUZE, Gilles \& GUATTARI, Félix. Mil Platôs - v. 4. São Paulo, Editora 34, 2012, pp.11113. 
FARIAS, Joana Silva de Araújo. Modelando Parentes: sobre as redes de relações da ritxo(k)o entre os Karajá. Dissertação de Mestrado em Antropologia Social, Universidade de São Paulo, 2015.

FAUSTO, Carlos. Se Deus fosse jaguar: canibalismo e cristianismo entre os Guarani (séculos XVI-XX). Mana. Rio de Janeiro, 2005, 11(2): 385-418.

GALLOIS, Dominique Tilkin. Traduções e aproximações indígenas à mensagem cristã. Cadernos de Tradução, 2012, v. 2, n. 30, p. 63-82.

HOLBRAAD, Martin. The power of powder: multiplicity and motion in the divinatory cosmology of Cuban Ifá. In: HENARE, Amiria; HOLBRAAD, Martin \& WASTELL, Sari (orgs.), Thinking through things: theorising artefacts ethnographically. London, Routledge, 2007, pp. 189-225.

JOÃO, Izaque. Jakaira reko nheypyru marangatu mborahéi: origem e fundamentos do canto ritual Jerosy Puku entre os Kaiowá de Panambi, Panambizinho e Sucuriy. Dissertação de Mestrado em História, Universidade Federal da Grande Dourados, 2011.

LATOUR, Bruno. Jamais fomos modernos. Rio de Janeiro: Editora 34, 1994 [1991].

Reflexão sobre o Culto Moderno dos Deuses Fe(i)tiches. Bauru, EDUSC, 2002 [1996].

LÉVI-STRAUSS, Claude. 2003. Introdução à obra de Marcel Mauss. In: MAUSS, Marcel. Sociologia e antropologia, São Paulo, Cosac \& Naify, 2003.

LOLLI, Pedro Augusto. O contínuo e o descontínuo em Lévi-Strauss. Dissertação de Mestrado em Antropologia Social, Universidade Estadual de Campinas, 2005.

MACHADO, João \& PEREIRA, Levi Marques. Nomes de parentela, rezas, artefatos de uso ritual e produção dos espaços dos tekoha: uma abordagem dos processos de reprodução social entre os kaiowá atuais a partir da memória de séries sociológicas e séries cosmológicas. In: PEREIRA, Levi Marques; SILVESTRE, Célia Foster; CARIAGA, Diógenes Egídio (orgs). Saberes, Sociabilidades, Formas Organizacionais e Territorialidades entre os Kaiowá e os Guarani em Mato Grosso do Sul. Dourados, Editora UFGD, prelo.

MELIÁ, Bartomeu; GRÜNBERG, Georg; GRÜNBERG, Friedl. Etnografia Guaraní del Paraguay Contemporaneo: Los Pai-Tavyterã. Assunción, CEADUC, 2008.

MORAIS, Bruno Martins. Do Corpo ao Pó: crônicas da territorialidade Kaiowa e Guarani nas adjacências da morte. São Paulo, Editora Elefante, 2017.

MURA, Fábio. A trajetória dos chiru na construção da tradição de conhecimento Kaiowa. Mana. Rio de Janeiro, 2010, 16(1): 123-150.

PEREIRA, Levi Marques. Imagens Kaiowá do Sistema Social e seu Entorno. Tese de Doutorado em Antropologia Social, Universidade de São Paulo, 2004.

PIERRI, Daniel Calazans. O dono da figueira e a origem de Jesus: uma crítica xamânica ao cristianismo. Revista de Antropologia, São Paulo, 2014, 57 (1): 265301.

SAHLINS, Marshall. Metáforas históricas e realidades míticas. Estrutura nos primórdios da história do reino das ilhas Sandwich. Rio de Janeiro, Editora Zahar, 2008 [1981]. 
SERAGUZA, Lauriene. Cosmos, Corpos e Mulheres Kaiowá e Guarani. De Aña à Kuña. Dissertação de Mestrado em Antropologia Social, Universidade Federal da Grande Dourados, 2013.

SCHADEN, Egon. Aspectos Fundamentais da Cultura Guarani. São Paulo, EDUSP, 1974 [1954].

. Religião Guarani e Cristianismo. Revista de Antropologia. São Paulo, 1982. (25): 1-24.

SZTUTMAN, Renato. Natureza e cultura, versão americanista - um sobrevoo. Ponto Urbe - Revista do Núcleo de Antropologia Urbana da USP, São Paulo, 2009, v. 3, n. 4, p. 1-23.

VIETTA, Katya. Histórias sobre terras e xamãs kaiowa: territorialidade e organização social na perspectiva dos Kaiowa de Panambizinho (Dourados, MS) após 170 de exploração e povoamento não indígena da faixa entre Brasil e Paraguai. Tese de Doutorado em Antropologia Social, Universidade de São Paulo, 2007.

VIVEIROS DE CASTRO, Eduardo. O nativo relativo. Mana. Rio de Janeiro, 2002, 8(1):113-148.

. Perspectival anthropology and the method of controlled equivocation. Tipití (Journal of the Society for the Anthropology of Lowland South America), 2004, 2(1):3-22.

. Metafísicas caníbales. Líneas de Antropología Posestructural. Madri, Katz Editores, 2010.

ZEA, Evelyn Schuler. Genitivo da Tradução. Boletim Museu Emílio Goeldi, Belém, 2008, v. 3, n. 1, p. 65-77. 